\title{
the 1-Methyl-4-phenyl-1, 2, 3, 6-tetrahydropyridine-Induced Mouse Model of Parkinson's Disease
}

\author{
Chuanfeng Lv, ${ }^{1}$ Tie Hong, ${ }^{1}$ Zhen Yang, ${ }^{2}$ Yu Zhang, ${ }^{1}$ Lu Wang, ${ }^{3}$ Man Dong, ${ }^{1}$ Jing Zhao, ${ }^{1}$ \\ Jiaye $\mathrm{Mu}^{3}$ and Yixiao Meng ${ }^{3}$ \\ ${ }^{1}$ Department of Pharmacology, School of Pharmacy, Jilin University, Changchun 130021, China \\ ${ }^{2}$ Institute of Changbai Mountain Natural Resources, Jilin Academy of Chinese Medicine Sciences, Changchun 130012, China \\ ${ }^{3}$ College of Pharmacy, Yanbian University, Yanji 133002, China
}

Correspondence should be addressed to Tie Hong, hongtie@jlu.edu.cn

Received 17 September 2011; Revised 5 November 2011; Accepted 7 November 2011

Academic Editor: Mahmud Tareq Hassan Khan

Copyright (c) 2012 Chuanfeng Lv et al. This is an open access article distributed under the Creative Commons Attribution License, which permits unrestricted use, distribution, and reproduction in any medium, provided the original work is properly cited.

\begin{abstract}
In this paper, the protective effect of the bioflavonoid quercetin on behaviors, antioxidases, and neurotransmitters in 1-methyl-4phenyl-1, 2, 3, 6-tetrahydropyridine-(MPTP-) induced Parkinson's disease (PD) was investigated. Quercetin treatment (50 mg/kg, $100 \mathrm{mg} / \mathrm{kg}$ and $200 \mathrm{mg} / \mathrm{kg}$ body weight) was orally administered for 14 consecutive days. The results show that quercetin treatment markedly improves the motor balance and coordination of MPTP-treated mice. Significant increases were observed in the activities of glutathione peroxidase (GPx), superoxide dismutase (SOD), and $\mathrm{Na}^{+}, \mathrm{K}^{+}$-ATPase, AchE, the content of dopamine (DA) in the quercetin plus MPTP groups compared to those in the MPTP group. Significant reduction the 4-hydroxy-2-nonenal (4-HNE) immunoreactivity in striatum of brains was observed in the quercetin plus MPTP groups in comparison to the MPTP group. Taken together, we propose that quercetin has shown antiparkinsonian properties in our studies. More work is needed to explore detailed mechanisms of action.
\end{abstract}

\section{Introduction}

Parkinson's disease $(\mathrm{PD})$, which is a type of regressive disease of the central nervous system, is the second most common disorder of the aging brain after Alzheimer's disease. The clinical manifestations are static tremors, myotonia, bradykinesia, and poor balance. The main drug families that are useful for treating motor symptoms are levodopa, dopamine agonists, and MAO-B inhibitors [1].

PD models are divided into two broad categories: genetic and toxic $[2,3]$. Most of the data that addresses the effects of oxidative stress have been generated using toxic models such as those produced by 1-methyl-4-phenyl-1, 2, 3, 6hydroxydopamine (MPTP), which damages the nigrostriatal dopaminergic system.

The antioxidative activity of quercetin, which is a bioflavonoid, has been studied [4]. Recent studies have shown that quercetin crosses the blood-brain barrier (BBB) [5] and protects HT-22 cells by prohibiting the formation of reactive oxygen species (ROS), which is generated by glutamic acid-induced oxidation toxicity and lipid peroxidation [6].

In the present study, we investigated the neuroprotective effects of quercetin to modify glutathione peroxidase (GPx), superoxide dismutase (SOD), $\mathrm{Na}^{+}, \mathrm{K}^{+}$-ATPase, immunoreactivity of 4-hydroxy-2-nonenal (4-HNE), acetylcholinesterase (AChE) activities, and the level of dopamine (DA) in the brain tissue in the MPTP-induced mouse model of Parkinson's disease.

\section{Materials and Methods}

2.1. Animals. Specific pathogen-free adult male C57BL/6 mice $(25 \pm 2 \mathrm{~g}$, body weight; $2-2.5$ months old) were housed in standard cages with wood shavings. Ten animals per cage were kept in a room with a carefully controlled ambient temperature $\left(25^{\circ} \mathrm{C}\right)$ and artificially illumination 


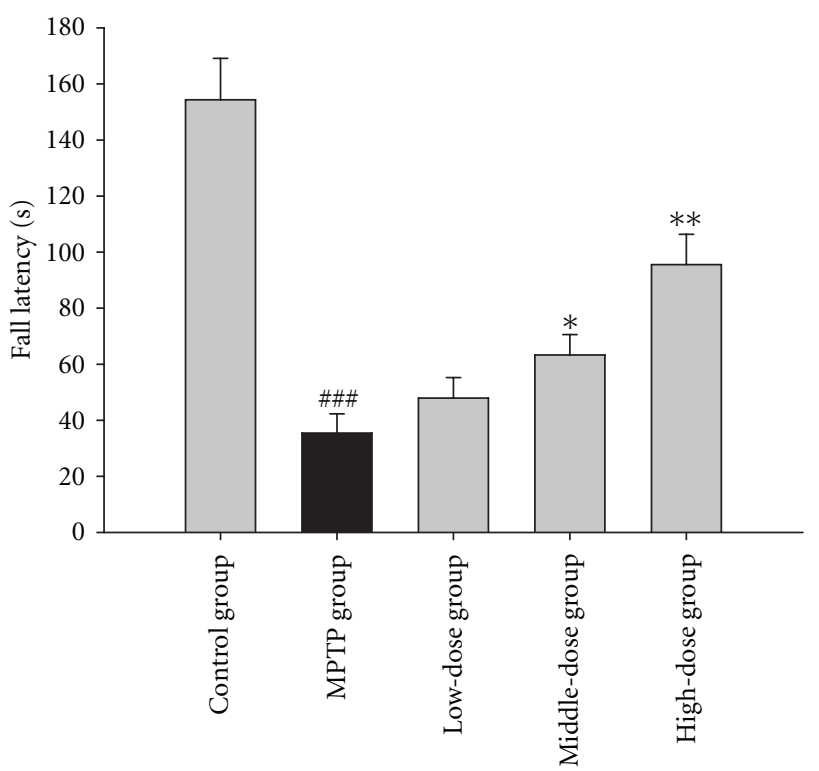

FIGURE 1: The effect of quercetin on the fall latency of rotarod test in a mice model of Parkinson's disease (PD) induced by MPTP. Data were expressed as mean \pm SE for 10 mice in each group. \#\#: $P<$ 0.001 as compared to the control group; ${ }^{*}: P<0.05$ as compared to MPTP group; ${ }^{* *}: P<0.01$ as compared to MPTP group.

(12 hours of light from 8:00 AM to 8:00 PM). All experiments were performed under the Guidelines of the Experimental Laboratory Animal Committee of the Jilin Province.

2.2. Drugs. Quercetin (98\%) and MPTP were purchased from Sigma-Aldrich (St. Louis, MO, USA). All of the other chemicals were of analytical grade and obtained from standard commercial suppliers. MPTP was dissolved in $0.9 \%$ physiological saline, and quercetin was resuspended in distilled water.

2.3. Animal Grouping and Treatment. The mice were divided into 5 groups (10 mice in each group): the control group, the MPTP group (MPTP-treatment group), the low-dose group (quercetin $50 \mathrm{mg} / \mathrm{kg}$ body weight plus MPTP), the middle-dose group (quercetin $100 \mathrm{mg} / \mathrm{kg}$ body weight plus MPTP), and the high-dose group (quercetin $200 \mathrm{mg} / \mathrm{kg}$ body weight plus MPTP). All quercetin plus MPTP groups were orally administered the indicated concentration of quercetin every $24 \mathrm{~h}$ for 14 consecutive days. To evaluate the effects of quercetin in the PD mouse model, MPTP was intraperitoneally injected with five consecutive injections at a dose of $30 \mathrm{mg} / \mathrm{kg}$ every $24 \mathrm{~h}$ from day 10 to day 14 starting at $1 \mathrm{~h}$ after the oral administration of quercetin. An equal volume of saline instead of MPTP was injected into the mice in the control group.

2.4. Motor Behavior Analysis with the Rotarod Test. An accelerating rotarod test was used to measure motor balance and coordination in mice as described previously by L'Episcopo et al. [7]. The rotarod cylinder was accelerated from 4

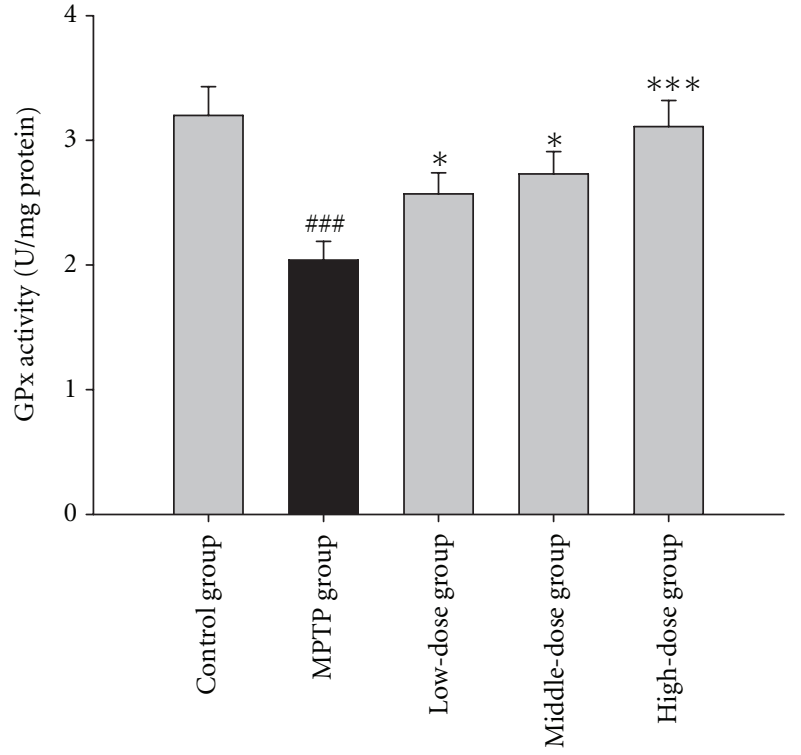

FIGURE 2: The effects of quercetin on the activity of glutathione peroxidase in a mice model of Parkinson's disease (PD) induced by MPTP. Data were expressed as mean \pm SE for 10 mice in each group. ${ }^{\# \#}: P<0.001$ as compared to the control group; ${ }^{*}: P<0.05$ as compared to MPTP group; ${ }^{* *}: P<0.001$ as compared to MPTP group.

to $40 \mathrm{rpm}$ within 5 minutes, and the cutoff time was 300 seconds. The total time that each mouse remained on the rod was automatically recorded by a trip switch under the floor of each rotating drum that was activated by the animal's fall. The average time (fall latency) for three trials was determined.

2.5. Tissue Sample. The mice were sacrificed after being anesthetized with pentobarbital sodium. The brain tissue was isolate removed and divided equably into two parts.

One part of the brain tissues was immediately homogenized in cold $10 \mathrm{mM}$ Tris- $\mathrm{HCl}, \mathrm{pH} 7.5$ (1/10 w/v), with $10 \mathrm{up}-$ and-down strokes at approximately $12,000 \mathrm{rpm}$ in a Teflonglass homogenizer. The homogenates were centrifuged at $3000 \times \mathrm{g}$ for $10 \mathrm{~min}$ to yield a clear supernatant fraction as the sample that was used for measuring the activity of GPx, $\mathrm{SOD}, \mathrm{Na}^{+}, \mathrm{K}^{+}$-ATPase, and AChE.

The other part of the brains was transferred into a $1.5 \mathrm{~mL}$ plastic vial, then weighed and homogenized in icedcold $\mathrm{HClO}_{4}(0.4 \mathrm{M})$ using an ultrasonicator. After storage for $1 \mathrm{~h}$ in ice, the homogenates were centrifuged at $12,000 \times \mathrm{g}$ for $15 \mathrm{~min}$ at $4^{\circ} \mathrm{C}$. The supernatant was incubated with a mixed buffer $\left(20 \mathrm{mM}\right.$ sodium citrate, $300 \mathrm{mM} \mathrm{K} \mathrm{HPO}_{4}$, $2 \mathrm{mM}$ sodium ethylenediaminetetraacetic acid ( $\left.\mathrm{Na}_{2} \mathrm{EDTA}\right)$ ) at the ratio $(\mathrm{v} / \mathrm{v})$ of $1: 2$ for $1 \mathrm{~h}$ on ice and centrifuged at $12,000 \times \mathrm{g}$ for $15 \mathrm{~min}$ at $4^{\circ} \mathrm{C}$. The supernatant was collected and filtered through a $0.22 \mathrm{~mm}$ filter and was subsequently analyzed the level of the DA [8].

2.6. Biochemical Analysis. The GPx activity was determined in accordance with a previously described method [9] with 


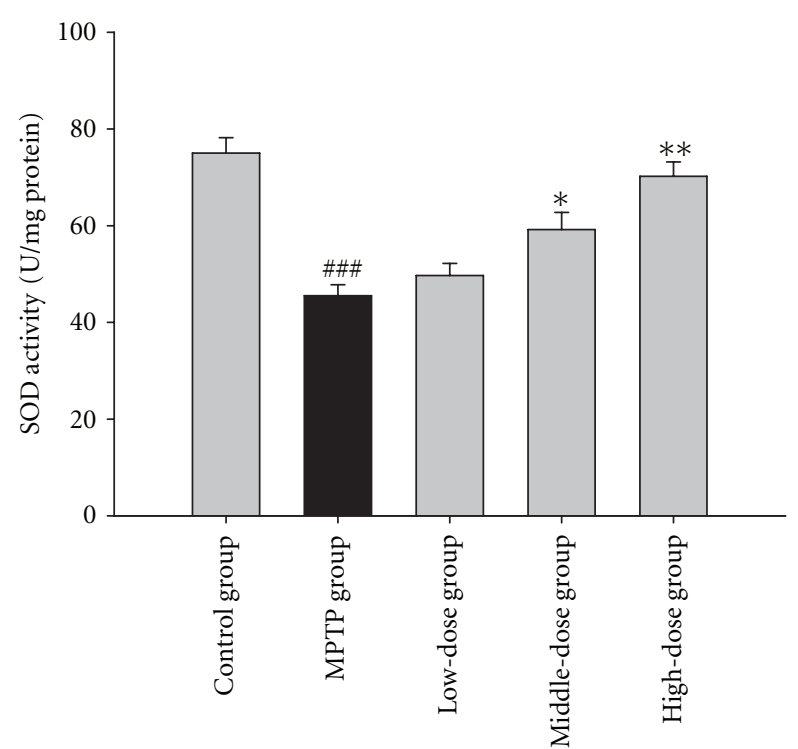

FIGURE 3: The effects of quercetin on the activity of superoxide dismutase in a mice model of Parkinson's disease (PD) induced by MPTP. Data were expressed as mean \pm SE for 10 mice in each group. ${ }^{\# \#}: P<0.001$ as compared to the control group; ${ }^{*}: P<0.05$ as compared to MPTP group; ${ }^{* *}: P<0.01$ as compared to MPTP group.

minor modifications. The enzymatic activity of GPx was represented as unit/mg protein, where 1 unit of GPx activity was defined as $1 \mu \mathrm{M}$ GSH that was depleted per minute.

The SOD activity was measured using the method of Ohkawa et al. [10] to evaluate the ability of the xanthinexanthine oxidase system to inhibit the oxidation of oxymine.

$\mathrm{Na}^{+}, \mathrm{K}^{+}$-ATPase activity was determined using method that has been described by Wyse et al. [11]. The reaction mixture for the $\mathrm{Na}^{+}, \mathrm{K}^{+}$-ATPase activity assay contained the following: $3 \mathrm{mM} \mathrm{MgCl}, 125 \mathrm{mM} \mathrm{NaCl}, 20 \mathrm{mM} \mathrm{KCl}$, and $50 \mathrm{mM}$ Tris- $\mathrm{HCl}(\mathrm{pH} 7.4$ ) in a final volume of $500 \mu \mathrm{L}$. The reaction was initiated by the addition of ATP to a final concentration of $3.0 \mathrm{mM}$. The control samples were obtained under the same conditions with the addition of $0.1 \mathrm{mM}$ ouabain. The samples were incubated at $37^{\circ} \mathrm{C}$ for $30 \mathrm{~min}$, and the incubation was stopped by adding trichloroacetic acid solution (10\% TCA) with $10 \mathrm{mM} \mathrm{HgCl}_{2} . \mathrm{Na}^{+}, \mathrm{K}^{+}$-ATPase activity was calculated based on the difference between the two assays (with ouabain/without ouabain). The specific activity of the enzyme was expressed as mol $\mathrm{Pi}$ that was released per hour per mg of protein (mol Pi/hour/mg protein).

The activity of acetylcholinesterase (AchE) was estimated using the method of Ellman et al. [12]. The samples were homogenized in buffer medium I $(0.32 \mathrm{M}$ sucrose, $5 \mathrm{mM}$ Tris- $\mathrm{HCl}$ and $0.1 \mathrm{mM}$ EDTA) $(1: 10 ; \mathrm{w} / \mathrm{v})$ and centrifuged at $2400 \times \mathrm{g}$ for $10 \mathrm{~min}$ to obtain the low-speed supernatant. The homogenate $(100 \mu \mathrm{L})$ was incubated in $1 \mathrm{~mL}$ of a solution containing $10 \mathrm{mM}$ 5,5-ditiobis (2-dinitrobenzoic) acid (DTNB) (dissolved in potassium phosphate buffer $\mathrm{pH}$ 7.0) and $100 \mathrm{mM}$ potassium phosphate buffer $(\mathrm{pH} 7.5)$ as well as $700 \mu \mathrm{L}$ water for $2 \mathrm{~min}$ at $25^{\circ} \mathrm{C}$. Afterwards, $200 \mu \mathrm{L}$

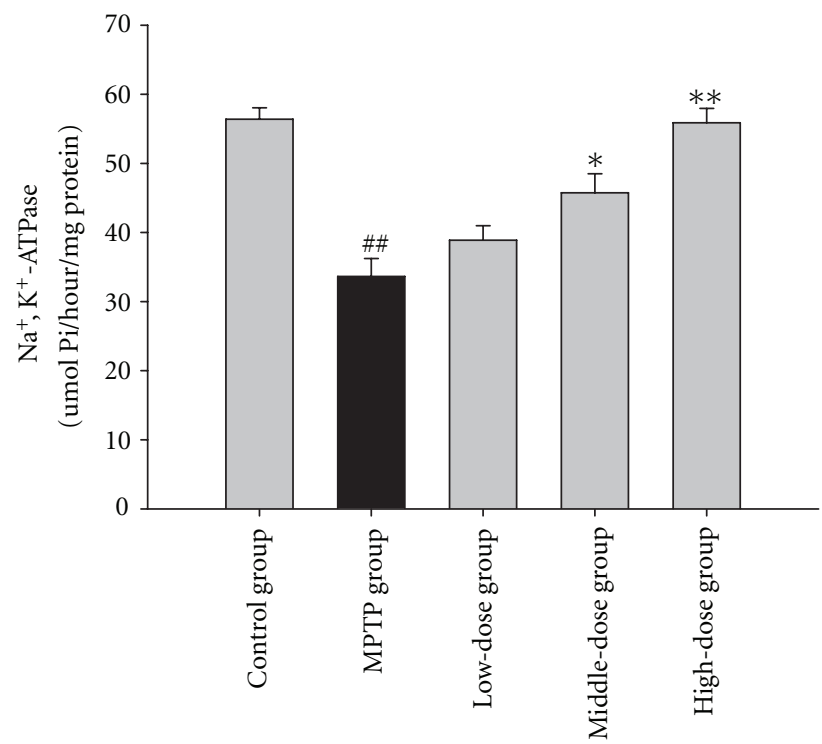

FIgURE 4: The effects of quercetin on the activity of $\mathrm{Na}^{+}, \mathrm{K}^{+}$-ATPase in a mice model of Parkinson's disease (PD) induced by MPTP. Data were expressed as mean \pm SE for 10 mice in each group. ${ }^{\#}: P<0.01$ as compared to the control group; ${ }^{*}: P<0.05$ as compared to MPTP group; ${ }^{* *}: P<0.01$ as compared to MPTP group.

of acetylthiocholine ( $8 \mathrm{mM}$, substrate) was added to the tube test. The activity of AchE was spectrofluorometrically measured at $412 \mathrm{~nm}$ and expressed as hydrolyzed Ach/min/mg protein.

The protein concentration was measured using the Bradford method [13] with bovine serum albumin as the standard.

The level of DA was determined using HPLC, which was equipped with an electrochemical (EC) detector that was used for quantification [8]. The level of DA was determined using standard curves as references. The data were expressed as ng/g tissue weight.

2.7. Immunohistochemistry. Immunohistochemical method was taken in another batch of mice which were treated as the "animal grouping and treatment." The brains were quickly removed and postfixed for 2 days with paraformaldehyde. Immunohistochemical studies were performed on paraffinembedded midbrain sections. The $30 \mu \mathrm{m}$ thick transverse sections were deparaffinized with xylene and refixed with Bouin's solution for $20 \mathrm{~min}$. For inhibition of endogenous peroxidase, the sections were incubated with $0.3 \% \mathrm{H}_{2} \mathrm{O}_{2}$ in methanol for $30 \mathrm{~min}$. After rinsing in $10 \mathrm{mM}$ phosphatebuffered saline (PBS), the sections were incubated with normal goat serum (Dako, diluted to $1: 10$ ) to inhibit nonspecific binding of the antibodies. After incubation with the polyclonal anti-4-hydroxy-2-nonenal (HNE) antibody (1:400, Alpha Diagnostic International, San Antonio, TX, USA) at $4^{\circ} \mathrm{C}$ overnight, the sections were treated with biotinylated secondary antibody for $1 \mathrm{~h}$ at $37^{\circ} \mathrm{C}$, then with streptavidin-peroxidase for $1 \mathrm{~h}$. Subsequently the sections were incubated with 3, 4-diaminobenzidine. The results were analyzed by counting the numbers of positive cells at $400 \mathrm{x}$ 


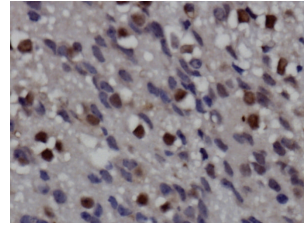

(a)

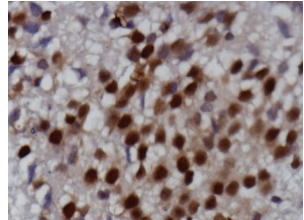

(b)

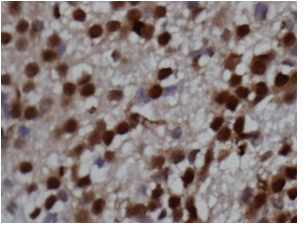

(c)

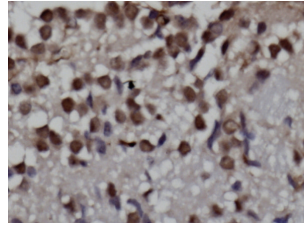

(d)

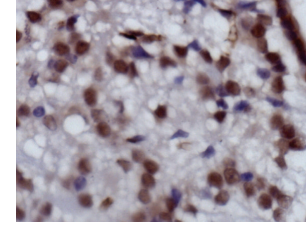

(e)

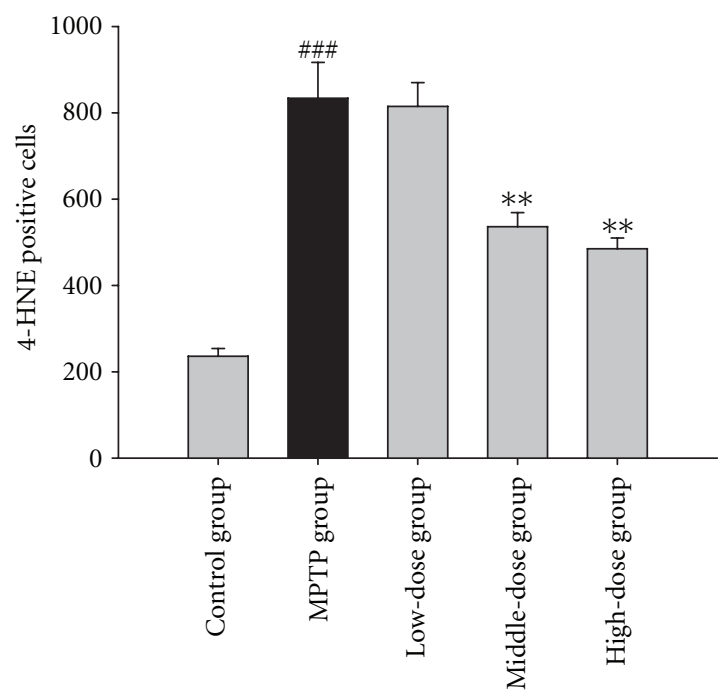

(f)

FIGURE 5: Immunostaining of striatum with 4-HNE in a mice model of Parkinson's disease (PD) induced by MPTP. Staining was present within cell bodies. ${ }^{\# \#}: P<0.001$ as compared to the control group: ${ }^{* *}: P<0.01$ as compared to MPTP group. (a) In control group, there was a few of 4-HNE immunoreactivity. (b) MPTP group: compared with control group, MPTP markedly increased the immunoreactivity of 4-HNE in mice striatum. (c) Low-dose group: no difference from MPTP group. (d) Middle-dose group: 4-HNE immunoreactivity are significantly reduced in striatum of brains in comparison to the MPTP group. (e) High-dose group: 4-HNE immunoreactivity are significantly reduced in striatum of brains in comparison to the MPTP group.

magnifications on a microscope (Eclipse 80i, Nikon Corp., Japan). The average number of positive cells was used to represent cell density.

2.8. Statistics. All of the data were expressed as the mean \pm SE. The statistical significance of differences that were detected in each parameter among the groups was evaluated using one-way analysis of variance (ANOVA) followed by Fisher's protected least significant difference (PLSD) comparison tests for post hoc $t$-tests.

\section{Results}

3.1. The Results of the Rotarod Test. In the rotarod test, the fall latency of the MPTP group was significantly shorter than that of the control group $(P<0.001)$. Compared with the MPTP group, the quercetin low-dose group showed no significant change whereas the middle- and high-dose groups exhibited significantly longer fall latencies $(P<0.05$ and $P<0.01$, resp.). The results are shown in Figure 1.

3.2. The Effect on Antioxidases. MPTP-treated mice displayed perturbations in the activities of GPx, SOD, and $\mathrm{Na}^{+}$,
$\mathrm{K}^{+}$-ATPase. Pretreatment with quercetin augmented the activities of GPx, SOD, and $\mathrm{Na}^{+}, \mathrm{K}^{+}$-ATPase in the mouse brain tissue. The results are shown in Figures 2, 3 and 4.

3.3. The Result of Immunohistochemistry. Immunoreactivity of 4-HNE was markedly increased in the striatum of the mice PD brain compared to the control group brain that displayed weak immunoreactivity of 4-HNE. We assessed the relationship of the antioxidant effect of quercetin in PD mice through phenotypic observation along with 4HNE using microscopy. Quercetin $(100,200 \mathrm{mg} / \mathrm{kg})$ reduced the immunoreactivity of 4-HNE in the striatal neurons of C57/BL mice. All results shown in Figure 5.

3.4. The Effect on AchE. We analyzed the effects of quercetin on the activity of AchE in the brain tissues. AchE was lower in the MPTP group than in the control group. AchE in administration of quercetin groups showed higher than that MPTP group. The results were showed in Figure 6.

3.5. The Effect of the Level of DA. The effects of quercetin on the levels of DA in the brain are shown in Figure 7. The brain levels of DA decreased in the MPTP group compared 


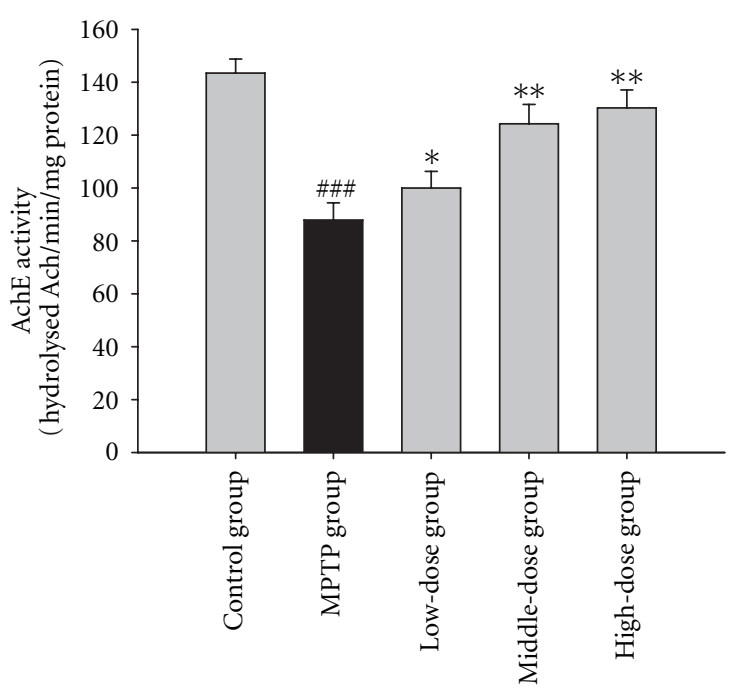

FIGURE 6: The effects of quercetin on the activity of acetylcholinesterase in a mice model of Parkinson's disease (PD) induced by MPTP. Data were expressed as mean \pm SE for 10 mice in each group. ${ }^{\# \#}: P<0.001$ as compared to the control group; ${ }^{*}: P<0.05$ as compared to MPTP group; ${ }^{* *}: P<0.01$ as compared to MPTP group.

to the control group $(P<0.01)$. Compared with the MPTP group, the quercetin pretreatment groups attenuated the MPTP-induced DA depletion.

\section{Discussion}

MPTP is metabolized into the toxic cation 1-methyl-4phenylpyridinium (MPP+) by the enzyme MAO-B in glial cells. MPP+ primarily kills dopamine-producing neurons in the part of the brain that is called the pars compacta of the substantia nigra and interferes with a component of mitochondrial metabolism, which induces cell death and causes the buildup of free radicals and toxic molecules [14].

The rotarod test is designed to evaluate the motor coordination and balance of the mouse by forcing the animal to run. In the present study, the results of the rotarod test reveal that the quercetin concentrations at the middle $(100 \mathrm{mg} / \mathrm{kg})$ or high $(200 \mathrm{mg} / \mathrm{kg})$ doses enhance the motor activity of MPTP-treatment mice. This finding shows that quercetin plays an important role in the developmental processes of the internal system regulating the mouse motor behavior and suggests that quercetin improves the balance of MPTP-treatment mice.

Recent research has suggested that the brain may efficiently metabolize superoxide but may have difficulties regarding hydrogen peroxide elimination [15]. In this study, the MPTP group showed lower GPx and SOD activities. These results indicate that MPTP reduces the elimination of hydrogen peroxide and free radicals in the brain. Quercetin pretreatment in the MPTP-induced group showed increased GPx and SOD activities. These results suggest that the elimination of superoxide anion was enhanced by quercetin. Hydrogen peroxide, which is generated during superoxide

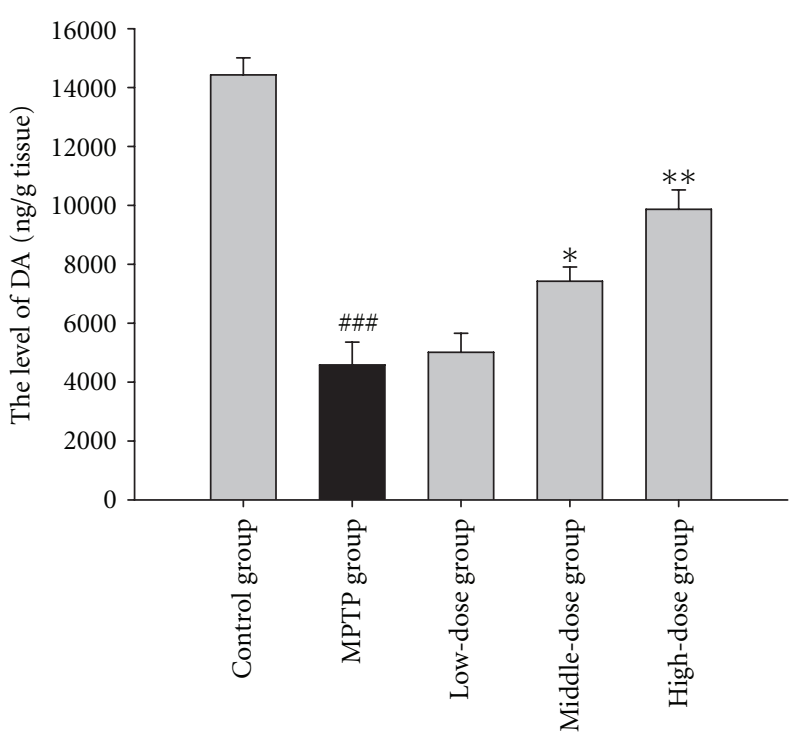

FIGURE 7: The effects of quercetin on the level of dopamine in a mice model of Parkinson's disease (PD) induced by MPTP. Data were expressed as mean $\pm \mathrm{SE}$ for 10 mice in each group. ${ }^{\# \#}: P<0.001$ as compared to the control group; ${ }^{*}: P<0.05$ as compared to MPTP group; $^{* *}: P<0.01$ as compared to MPTP group.

dismutation, was sufficiently removed by GPx after the pretreatment with quercetin. 4-HNE is a major membrane lipid peroxidation product [16]. Additionally, we analyzed the effect of quercetin on the level of 4 -HNE in striatal neurons. As expected, quercetin (100, $200 \mathrm{mg} / \mathrm{kg}$ body weight) reduced the 4-HNE immunoreactivity in neurons of PD model mice. It shows that quercetin could decrease the product of lipid peroxidation. These results indicate the mechanism of quercetin neuroprotection effects.

The $\mathrm{Na}^{+}, \mathrm{K}^{+}$-ATPase establishes the ionic concentration balance that maintains the cell's potential. Recent research has suggested that the $\mathrm{Na}^{+}, \mathrm{K}^{+}$-ATPase is susceptible to free radical-induced damage [17]. In addition, $\mathrm{Na}^{+}, \mathrm{K}^{+}$-ATPase activity is reduced in disorders of the nervous system. $\mathrm{Na}^{+}$, $\mathrm{K}^{+}$-ATPase activity was examined. The results show that $\mathrm{Na}^{+}, \mathrm{K}^{+}$-ATPase activity is significantly reduced in the MPTP group compared to that in the control group. Quercetin reversed the MPTP-induced reduction in $\mathrm{Na}^{+}, \mathrm{K}^{+}$-ATPase activity. This result indicates that quercetin protects against MPTP-induced oxidative stress and maintains the resting membrane potential of neurons.

Dopamine and acetylcholine, which play important roles in bodily movement, should maintain the dynamic equilibrium in the extrapyramidal system. Sufferers of PD experience dystonia when the cholinergic nerve is placed in an advantage status. AchE is an enzyme that degrades (via its hydrolytic activity) the neurotransmitter Ach. Acetylcholine behaves as an excitatory neurotransmitter at neuromuscular junctions [18]. In the current study, we examined the activity of AchE in the brain tissue of mice. We found that the AchE activity in the MPTP group significantly decreased compared with the control group and that quercetin reversed the MPTP-induced reduction in AchE activity. This result 
suggests that quercetin reduces the level of acetylcholine by enhancing the AchE activity, which may mediate quercetininduced improvements in motor balance and coordination of MPTP-treated mice.

Dopamine is the primary neurotransmitter that is involved in motor functions. The loss of dopamine directly affects physical movements and is considered a cardinal feature of PD in humans or in animal models of the disease [19]. MPTP causes a significant reduction in brain dopamine levels. The results of our present study show that the administration of quercetin markedly improves MPTP-induced dopamine depletion in the brain tissue which is significantly altered following MPTP treatment. The enhancement of dopamine content by quercetin may restore the changes in locomotor activity.

\section{Conflict of Interests}

All authors manifest that there is no conflict of interests.

\section{References}

[1] D. Heisters, "Parkinson's: symptoms, treatments and research," British Journal of Nursing, vol. 20, no. 9, pp. 548-554, 2011.

[2] R. D. Prediger, A. S. Aguiar Jr., E. L.G. Moreira et al., "The intranasal administration of 1-methyl-4-phenyl-1,2,3,6tetrahydropyridine (mptp): a new rodent model to test palliative and neuroprotective agents for parkinson's disease," Current Pharmaceutical Design, vol. 17, no. 5, pp. 489-507, 2011.

[3] F. Cicchetti, J. Drouin-Ouellet, and R. E. Gross, "Environmental toxins and Parkinson's disease: what have we learned from pesticide-induced animal models?" Trends in Pharmacological Sciences, vol. 30, no. 9, pp. 475-483, 2009.

[4] A. Ishisaka, S. Ichikawa, H. Sakakibara et al., "Accumulation of orally administered quercetin in brain tissue and its antioxidative effects in rats," Free Radical Biology and Medicine, vol. 51, no. 7, pp. 1329-1336, 2011.

[5] K. A. Youdim, M. Z. Qaiser, D. J. Begley, C. A. Rice-Evans, and N. J. Abbott, "Flavonoid permeability across an in situ model of the blood-brain barrier," Free Radical Biology and Medicine, vol. 36, no. 5, pp. 592-604, 2004.

[6] K. Ishige, D. Schubert, and Y. Sagara, "Flavonoids protect neuronal cells from oxidative stress by three distinct mechanisms," Free Radical Biology and Medicine, vol. 30, no. 4, pp. 433-446, 2001.

[7] F. L'Episcopo, C. Tirolo, S. Caniglia et al., "Combining nitric oxide release with anti-inflammatory activity preserves nigrostriatal dopaminergic innervation and prevents motor impairment in a 1-methyl-4-phenyl-1,2,3,6tetrahydropyridine model of Parkinson's disease," Journal of Neuroinflammation, vol. 7, article 83, 2010.

[8] S. Li and X. P. Pu, "Neuroprotective effect of kaempferol against a 1-methyl-4-phenyl-1,2,3,6- tetrahydropyridineinduced mouse model of Parkinson's disease," Biological and Pharmaceutical Bulletin, vol. 34, no. 8, pp. 1291-1296, 2011.

[9] J. T. Rotruck, A. L. Pope, H. E. Ganther, A. B. Swanson, D. G. Hafeman, and W. G. Hoekstra, "Selenium: biochemical role as a component of glatathione peroxidase," Science, vol. 179, no. 4073, pp. 588-590, 1973.
[10] H. Ohkawa, N. Ohishi, and K. Yagi, "Assay for lipid peroxides in animal tissues by thiobarbituric acid reaction," Analytical Biochemistry, vol. 95, no. 2, pp. 351-358, 1979.

[11] A. T. S. Wyse, M. Wajner, A. Brusque, and C. M. D. Wannmacher, "Alanine reverses the inhibitory effect of phenylalanine and its metabolites on $\mathrm{Na}^{+}, \mathrm{K}^{+}$-ATPase in synaptic plasma membranes from cerebral cortex of rats," Biochemical Society Transactions, vol. 23, no. 2, p. 227, 1995.

[12] G. L. Ellman, K. D. Courtney, V. Andres, and R. M. Featherstone, "A new and rapid colorimetric determination of acetylcholinesterase activity," Biochemical Pharmacology, vol. 7, no. 2, pp. 88-95, 1961.

[13] Z. Q. Su, S. H. Wu, H. L. Zhang, and Y. F. Feng, "Development and validation of an improved Bradford method for determination of insulin from chitosan nanoparticulate systems," Pharmaceutical Biology, vol. 48, no. 9, pp. 966-973, 2010.

[14] C. Röhl, E. Armbrust, E. Herbst et al., "Mechanisms involved in the modulation of astroglial resistance to oxidative stress induced by activated microglia: antioxidative systems, peroxide elimination, radical generation, lipid peroxidation," Neurotoxicity Research, vol. 17, no. 4, pp. 317-331, 2010.

[15] T. Ito, K. Suzuki, K. Uchida, and H. Nakayama, "Different susceptibility to 1-methyl-4-phenylpyridium $\left(\mathrm{MPP}^{+}\right)$-induced nigro-striatal dopaminergic cell loss between C57BL/6 and $\mathrm{BALB} / \mathrm{c}$ mice is not related to the difference of monoamine oxidase-B (MAO-B)," Experimental and Toxicologic Pathology. In press.

[16] J. Lee, B. Kosaras, S. J. Del Signore et al., "Modulation of lipid peroxidation and mitochondrial function improves neuropathology in Huntington's disease mice," Acta Neuropathologica, vol. 121, no. 4, pp. 487-498, 2010.

[17] G. J. Lees, A. Lehmann, M. Sandberg, and A. Hamberger, "The neurotoxicity of ouabain, a sodium-potassium ATPase inhibitor, in the rat hippocampus," Neuroscience Letters, vol. 120, no. 2, pp. 159-162, 1990.

[18] P. Mohseni, H. K. Sung, A. J. Murphy et al., "Nestin is not essential for development of the CNS but required for dispersion of acetylcholine receptor clusters at the area of neuromuscular junctions," Journal of Neuroscience, vol. 31, no. 32, pp. 11547-11552, 2011.

[19] Y. S. Lau, G. Patki, K. Das-Panja, W. -D. Le, and S. O. Ahmad, "Neuroprotective effects and mechanisms of exercise in a chronic mouse model of Parkinson's disease with moderate neurodegeneration," European Journal of Neuroscience, vol. 33, no. 7, pp. 1264-1274, 2011. 


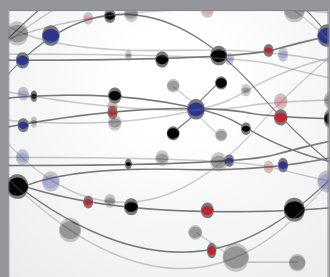

The Scientific World Journal
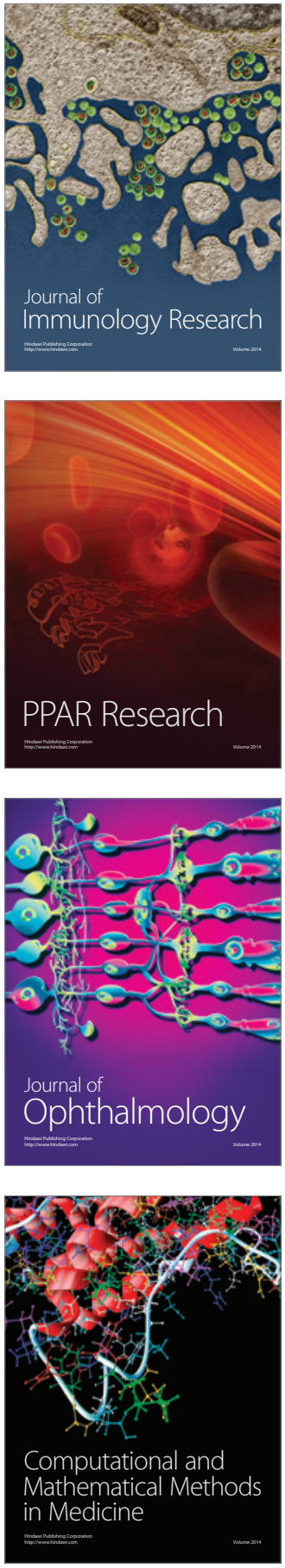

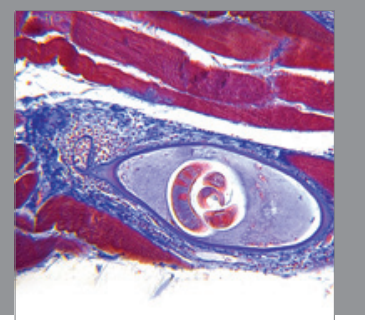

Gastroenterology

Research and Practice
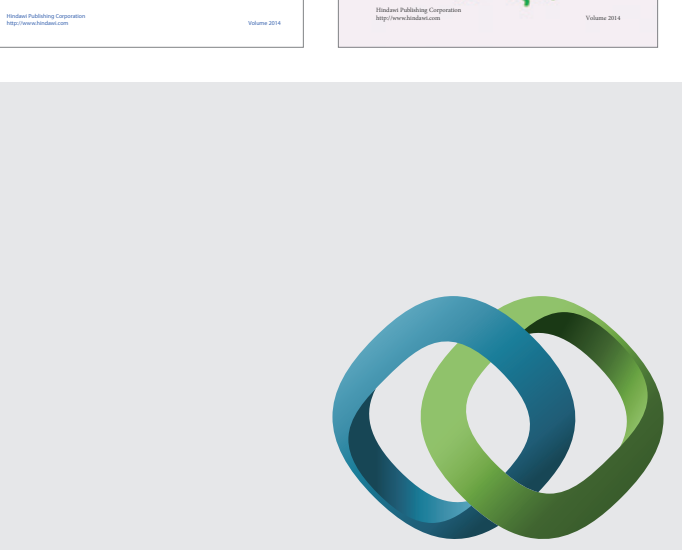

\section{Hindawi}

Submit your manuscripts at

http://www.hindawi.com
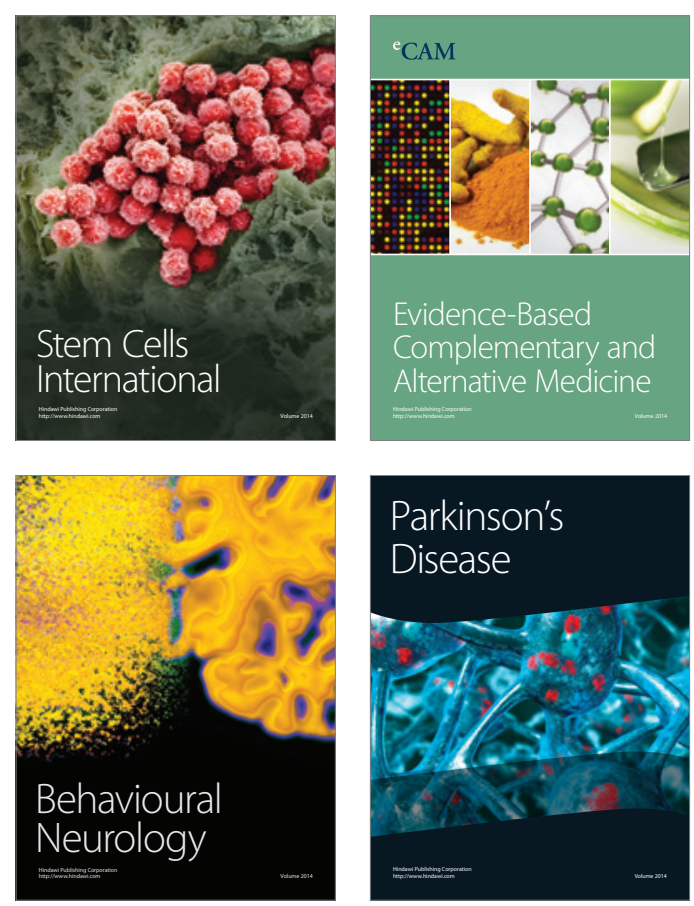

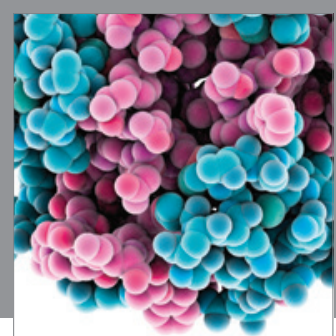

Journal of
Diabetes Research

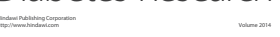

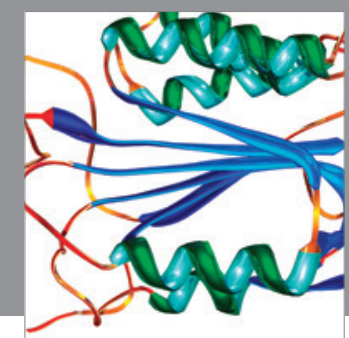

Disease Markers
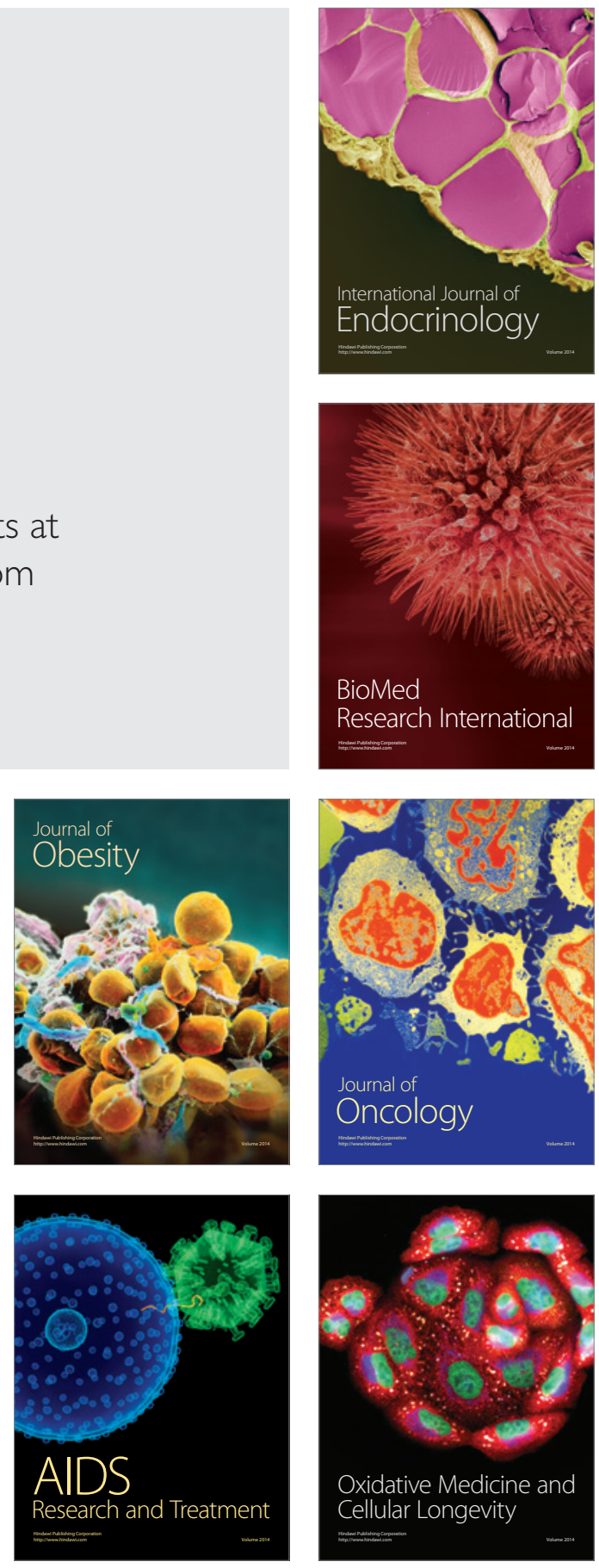